\title{
Tensiones y reformulaciones en torno a las masculinidades en el policial negro en Últimos días de la víctima de José Pablo Feinmann
}

Andrea Vilariño

Consejo Nacional de Investigaciones Científicas y Técnicas - Universidad de Buenos Aires / Universidad Nacional Arturo Jauretche, Argentina vilarinoandrea@yahoo.com.ar

\author{
María Laura Pérez \\ Consejo Nacional de Investigaciones Científicas y Técnicas - Universidad \\ de Buenos Aires, Argentina \\ mlauraperez83@gmail.com
}

Recibido: 7/8/2020. Aceptado: 15/4/2020.

\begin{abstract}
Resumen
Últimos días de la víctima es una novela escrita por José Pablo Feinmann en 1979. En general, la novela ha sido leída por la crítica en clave política (Gandolfo, 1986; Lafforgue y Rivera, 1997; Calabrese, 2000; Jacovski, 2011). En este trabajo, nos proponemos aportar otra arista a esa lectura, vinculándola con las relaciones de jerarquía y masculinidad entre los personajes. Al mismo tiempo, intentaremos problematizar la construcción de la masculinidad en el personaje de Mendizábal, ya que se encuentra constantemente tensionada tanto por la relación obsesiva que entabla con su objetivo, Külpe, como por la mirada de su rival, Peña.
\end{abstract}

Palabras clave: novela; policial negro; perspectiva de género; masculinidad; literatura argentina.

Tensions and reformulations around hardboiled's masculinities in Últimos dias de la victima, by José Pablo Feinmann

\begin{abstract}
Últimos dias de la víctima is a novel written by José Pablo Feinmann in 1979. Canonically, the novel has been read by critics through a political view (Gandolfo, 1986; Lafforgue y Rivera, 1997; Calabrese, 2000; Jacovski, 2011). In this work, we intend to add another perspective to that reading, thinking of the relationships of hierarchy and masculinity among the characters. At the same time, we will problematize the construction
\end{abstract}


of masculinity in the character of Mendizábal, because it is constantly strained not only by the obsessive relationship between Mendizábal and Külpe, but also by the gaze of his rival, Peña.

Keywords: Novel; Hardboiled; Gender; Masculinity; Argentinian Literature.

\section{Policial y masculinidad}

Últimos días de la víctima es considerada uno de los exponentes más relevantes del policial negro o hardboiled en nuestro país durante la década del setenta y principios de los ochenta (Lafforgue y Rivera, 1997: 30; Giardinelli, 2013: 242). Como señala Jorge Lafforgue, "con sus policiales Feinmann se ubicó en la línea de fuego" (2016: 46) al publicar sus dos novelas más notables, Últimos días de la víctima (1979) y Ni el tiro del final (1981), durante el último período de la dictadura militar (1976-1983). Las vinculaciones entre el género y la violencia de Estado han sido analizadas por varios autores (Gandolfo, 1986; Lafforgue, 1988; Calabrese, 2000; Jacovski, 2011), e incluso por el mismo Feinmann en su artículo "Estado policial y novela negra" (1991). El texto rastrea la representación del Estado en las novelas de Juan Martini, Osvaldo Soriano, Alberto Laiseca, Juan Sasturain y en las propias. Al comienzo del artículo encontramos una idea acerca de la caracterización de la institución policial en la narrativa del género y los motivos de la ausencia de detectives y policías en los relatos que, según el autor, se debe a la desconfianza hacia las fuerzas del orden en nuestro país. Sin embargo, este texto plantea que esta particularidad ha permitido que los escritores pudieran experimentar con respecto al género policial:

La policial argentina, en sus mejores expresiones, ha trabajado en los bordes del género y no dentro del género. Ha utilizado lo policial como elemento dinamizador del relato, como tensión, como mecanismo destinado a tironear la atención del lector (1991: 164).

La década de los setenta es importante para la literatura policial argentina ya que se publican varias novelas pertenecientes al género: Triste, solitario y final, de Osvaldo Soriano, El agua en los pulmones, de Juan Martini, Los tigres de la memoria, Juan Carlos Martelli (todas aparecidas en 1973). A las que pueden sumarse otras como Los asesinos las prefieren rubias (1974) y El cerco (1977), ambas de Juan Martini, Un dólar partido por la mitad (1975) de Sergio Sinay, Noches sin lunas ni soles (1975) de Rubén Tizziani, Su turno para morir (1976) de Alberto Laiseca.

A partir de esta lista de novelas y autores, Lafforgue y Rivera (1997) consideran que en los setenta aparecen textos que realizan operaciones literarias que "subvierten" el género:

Los narradores que se acercan al género a lo largo de los años ‘7o parecen acentuar la línea paródica, que borda sus florituras sobre tics, convenciones, manierismos, estilos y lenguajes que exigen, sobre todo, un público entrenado en el desciframiento y la fruición de cierto tipo de claves, aportadas por el cine "negro", la historieta, Hollywood, el erotismo de las pin up girls, la mitología del jazz, el revivalismo kitsch, el culto de los antihéroes, la novela "dura", la gestualidad Humphrey Bogart, la moda de los años “40, etcétera (1997: 94).

Según los autores hay una marcada tendencia en los setenta que retoma los temas del hardboiled y, mediante la experimentación de las formas y los temas, los transfigura.

1 En consonancia, Ezequiel De Rosso explica que lo que sucede, a partir de ese momento, es que la "voluntad de la forma desaparece" y, en consecuencia, "proliferan en los relatos dobles enfrentamientos, el enfrentamiento se 
Dentro de estas reescrituras, por supuesto, está también la de la figura del detective o, mejor dicho, de los protagonistas masculinos que se debatieron entre el héroe duro, pero moralmente irreprochable -vinculado a la obra de Chandler ${ }^{2}$ o la del detective que se contamina con el mundo del crimen -como lo hacen los de Hammett. ${ }^{3}$ En todos los casos, el modelo de masculinidad que se impone es el mismo:

Detectives, policías, fiscales, abogados, en fin 'La ley', triunfa no solo por sus deducciones o investigaciones, sino también por la bravura de sus miembros. Aunque con matices, esto es evidente en toda la moderna novela negra; y no solo respecto a los detectives, sino incluso de los transgresores y de las víctimas. Es decir: el hombre y su coraje, sus agallas y su temeridad, son circunstanciales a esta literatura. Desde el innominado detective de la Agencia Continental, este es un elemento exitoso y determinante para esta narrativa (Giardinelli, 2013:84)

El mundo del policial negro es un mundo de decisiones masculinas, donde las mujeres quedan a un lado, dice Elvio Gandolfo (1974: 97-98) acerca de El agua en los pulmones. La definición de Gandolfo es pertinente para pensar muchas otras obras en las que las mujeres no aparecen-Triste, solitario y final- o que son relegadas al lugar de acompañantes fieles -Noches sin lunas ni soles-, pero en ninguno de los casos presentan dificultades en torno a "las decisiones masculinas" que se toman. Más allá de la ausencia o presencia de las mujeres en las novelas del período, el mundo masculino se configura en relación con un mundo femenino. Ambos se moldean en torno a ciertos patrones que delimitan los comportamientos y prácticas de hombres y mujeres. En los relatos del género durante estos años, en nuestro país, no hay lugar para la construcción de otras subjetividades. El caso de Últimos días de la víctima es distinto debido a que se produce un desvío en relación con este modelo.

Desde esta perspectiva, nos proponemos analizar la novela Últimos días de la víctima, como una obra que, en consonancia con la serie literaria nacional del policial contemporáneo, se dispone a trabajar en los bordes del género. No obstante, explora otras formas de construcción de la masculinidad que se alejan de las configuraciones prototípicas del negro. En este sentido, consideramos que en la novela se produce una serie de desplazamientos que posibilitan la emergencia de otro tipo de masculinidad. Una masculinidad que puede leerse en términos de desvío respecto de las formas en las que el género ha construido su universo masculino.

Como ya hemos señalado, en tanto inscripta en el policial negro, la novela de Feinmann recupera el mundo complejo y violento de las producciones clásicas del género. Una violencia que se desarrolla, además, en un universo predominantemente masculino. Violencia y masculinidad son los ejes a partir de los cuales se construye este mundo. Cristopher Breu (2005: 1-22) sostiene que la masculinidad del hardboiled emerge y se consolida, entre 1920 y 1945 , como una identidad particular en la que confluyen diversas representaciones provenientes tanto de la ficción como de la vida cotidiana del período. Para Breu, las narrativas del género están convencionalmente organizadas a partir de dos ejes: uno homosocial y otro heterosexual. El componente de homosociabilidad está presente en el policial desde sus orígenes y da cuenta del tipo de relación particular que se establece entre los personajes masculinos en los primeros

construye a partir de amenazas múltiples que ya no provienen de la ley sino de otras fuerzas que pueden no ser propiamente criminales" (2018: 620).

2 Al respecto, Piglia señala: “En este sentido, yo diría que son novelas capitalistas en el sentido más literal de la palabra: deben ser leídas, pienso, ante todo como síntomas. Relatos llenos de contradicciones, ambiguos, que a menudo fluctúan entre el cinismo (ejemplo: James Hadley Chase) y el moralismo (en Chandler todo está corrompido menos Marlowe, profesional honesto que hace bien su trabajo y no se contamina; en verdad parece una realización urbana del cowboy)" (2015: 62).

3 Para una lectura más exhaustiva sobre los detectives del hardboiled véase Sebreli (1997) y Grella (1980). 
relatos. Los ejemplos más notorios han sido en la literatura los vínculos entre Dupin y el narrador de sus historias, o la clásica pareja formada por Sherlock y Watson. No obstante, para Breu esa relación homosocial en el negro alterna entre la competición y la confrontación. En efecto, las relaciones masculinas se presentan como antagónicas y derivan, la mayoría de las veces, hacia diversas formas de violencia. El eje heterosexual está organizado entre el hombre del hardboiled y la femmefatale. También es una relación marcada por la competencia y el conflicto, pero atravesada por el erotismo, que resitúa la confrontación en el plano de la atracción y el repudio.

Ambos ejes están presentes en el inicio de Últimos días de la víctima, aunque se irán transformando, de manera progresiva, a medida que avanza el relato. Este proceso derivará en una variación de la fórmula del relato negro clásico. La novela comienza con la visita de Mendizábal al "hombre importante" (que es quien le asignará el trabajo). En este encuentro, ya empiezan a delimitarse las características de estos hombres duros que habitan el hardboiled y cuyos rasgos centrales (violentos, dominantes, amorales, agresivos, competitivos, heterosexuales) están en sintonía con los valores de masculinidad que se reproducen en el modelo patriarcal (Connel, 1995: 31-48; Bourdieu, 2000: 31-62). Las relaciones jerárquicas al interior de esta comunidad masculina dan cuenta de una estructura rígida que permea sus relaciones y se funda en un lazo de homosociabilidad que, como señala Breu (2005), se expresa a través del enfrentamiento y la competencia. Esto puede verse en las escenas en las que Mendizábal concurre al encuentro con el "hombre importante" y en la distribución de los lugares en torno a esta figura de poder. En el primer encuentro, Mendizábal se sienta frente al hombre importante en la silla de terciopelo y sabe que ese lugar no solo significa su valor como profesional sino también como hombre:

él, Mendizábal, no era como los otros. Es decir: como los otros que iban a ese escritorio y permanecían allí, de pie, tiesos y asustados, respetuosos hasta la humillación, esperando una orden como quien necesita permiso, para, apenas, respirar (2013:11).

Mendizábal se mide de igual a igual con el hombre importante. En cambio, Peña permanece de pie, esperando órdenes.

Más adelante, Mendizábal será llamado nuevamente por el hombre importante, pero, en esta ocasión, su lugar será ocupado por Peña:

advirtió que la silla de terciopelo ya no estaba allí, como en la primera entrevista, esperándolo, invitándolo a sentarse en ella, a exhibir su orgullo y su jerarquía, sino que ahora había sido ubicada junto al hombre importante -es decir: del otro lado del escritorio-, y en ella [...] estaba sentado Peña (2013: 126). ${ }^{4}$

En ese sentido, lo que se vislumbra en el relato es que la distribución de los lugares es una marca de esta sociedad particular en la que los vínculos están atravesados por relaciones jerárquicas y dichas relaciones se sostienen en función del tipo de masculinidad que expresan. Robert Connel (1995) afirma que la masculinidad (como así la femineidad) es una categoría dinámica que "siempre está asociada a contradicciones internas y rupturas históricas" (1995: 38). El contexto histórico en el que se plantea la

4 Es interesante la relación que la novela de Feinmann establece con el cuento de Borges “El muerto”, ya que ambos trabajan sobre las relaciones de poder y lealtad. No obstante, en Últimos días de la víctima, dichas relaciones están reconfiguradas en dos pares: Peña/Mendizábal y Külpe/Mendizábal. Peña siempre quiere ocupar el lugar del hombre importante, a diferencia de Mendizábal quien jamás se plantea esta opción. Por otro lado, Külpe quiere ocupar el lugar de Mendizábal, pero éste último no lo sabe hasta el final. En el relato de Borges, Otárola, no comprende la trampa, pero conoce a su enemigo. Mendizábal, en cambio, cree conocer a su enemigo, pero se equivoca. Ambos personajes, Otárola y Mendizábal, no reconocen que su lugar dentro de la estructura de poder está siendo erosionado y solo lo vislumbran en el umbral de la muerte. 
diégesis de la novela es un período marcado por la violencia masculina, de carácter patriarcal. La sociedad que se representa es una sociedad jerárquica establecida a partir de relaciones de subordinación y dominación. En ese sentido, se asemeja a las instituciones militares y policíacas del período en las que se replican las formas de humillación y sometimiento para lograr la imposición de unos sobre otros. En relación con este "sujeto policial", Mariana Sirimarco (2004) sostiene que la subordinación es equiparada con la humillación y así puede erigirse la superioridad del otro. Este sistema de las escuelas policiales se traslada por lo tanto al Estado dictatorial (que es en ese momento quien gobierna). Por consiguiente, esta estructura de poder también se verá replicada, de alguna forma, en la organización a la que pertenece Mendizábal. Al mismo tiempo, Connel señala que "las prácticas organizacionales del Estado están estructuradas en relación al escenario reproductivo. [...] Y ese nexo con el Estado es social" (1995: 38). La organización para la que trabaja Mendizábal reproduce las relaciones genéricas del Estado porque reproduce los modos de establecer el poder.

Este modelo, en el que se dirimen relaciones de poder, está en consonancia con los propuestos dentro del género negro, que también construye un universo violento, jerárquico, atravesado por lógicas de dominación y sumisión. En el relato, los roles que ocupan los personajes se configuran a partir de estos esquemas (aunque esto se irá modificando con el transcurso de la narración). El poder es detentado por "el hombre importante" (personaje sin nombre que es reducido a mera función), alrededor del cual se posicionan, en clara rivalidad -en términos de Breu (2005) "competencia"-, Mendizábal y Peña. En esta primera instancia, la figura de Mendizábal se presenta en una escala superior a la de su rival. La contienda entre Mendizábal y Peña se plantea en relación con aquellos rasgos de masculinidad que se ponderan en dicha comunidad. En ese sentido, la hombría de cada uno se examina a través de ciertas conductas asumidas y, especialmente, a través de su sexualidad. En ninguno de estos dos aspectos, Mendizábal es capaz de expresar la hombría necesaria para disputar instancias de poder en esa organización. Si bien es percibido como uno más, como un duro, por la mayoría de las personas que lo rodean, ya que posee todas las características que marcan a este tipo de hombres -vive solo, tiene un trabajo peligroso, no se deja intimidar por otros-, hay otros aspectos en el personaje que atenúan esta condición. Es educado, disfruta de la música clásica, su trabajo se caracteriza por la pulcritud y se lo presenta como alguien distanciado de las pasiones. Mendizábal exhibe con orgullo su forma de trabajar y se define a sí mismo de la siguiente manera:

Un instrumento, a Mendizábal le gustaba definirse así. Lo hacía sentirse puro, incontaminado, ajeno a las pasiones de los demás. Y eficaz. Si alguna idea de justicia había en él, estaba dictada por su orgullo: quien lo llamaba merecía ganar, porque había elegido al mejor (2013: 54).

Estas cualidades, que son entendidas como positivas por Mendizábal (y también por el hombre importante), tienen otro significado para Peña, ya que las percibe como un signo de debilidad que se contrapone con la concepción de hombría de esa comunidad:

-Y es que siempre son así las cosas. Siempre, al principio, uno quiere ser como otro. -Miró a Mendizábal y agregó: -Eso a mí me pasó con usted. Pero no se ponga contento porque duró poco. Después me enteré de lo demás, de sus vueltas, sus manías, de todo el tiempo que perdía en boludeces. Y de las fotos, sobre todo de las

5 Sirimarco (2004) analiza cómo las alusiones sexuales y genéricas juegan un rol importante para la conformación del sujeto policial. Es decir, para la formación de los futuros agentes policiales. Debido a que, en la novela de Feinmann, Mendizábal y Peña trabajan en una organización criminal al servicio de los grupos parapoliciales, es pertinente relacionar esta categoría con los personajes y sus formas de afirmar sus lugares frente a los otros.

6 "Últimos días de la víctima aparece en plena, muy plena dictadura militar, en diciembre de 1979. La novela tiene una lectura -entre varias posibles, tal como, por ejemplo, El cerco- política” (Feinmann, 1991: 162). 
fotos. -Volvió a hacer una pausa aquí, como si buscara las palabras. Después dijo: -Porque, no sé, hay algo raro en eso de las fotos, algo de marica o de cana. Apenas me enteré le agarré bronca a usted, se me vino abajo (2013: 108-109).

El uso de la palabra marica para definir el trabajo de Mendizábal lo reubica en cuanto a su hombría, ya que no solo define su accionar, sino también a él como sujeto masculino. Como señala Sirimarco:

En estos discursos donde lo que se busca es doblegar al otro, los epítetos que aluden a la sexualidad revisten una forma particular de sometimiento. Tal vez porque la estructura de género no es sino una de las modalidades en que puede revelarse esta estructura de poder (2004: 65).

Entonces, las mariconerías de Mendizábal, en términos de Peña (2013: 107), sus vueltas, sus fotografías, ese método del cual se jacta es, para este personaje, una muestra de debilidad, que se lee como rasgo femenino. Peña entiende que esa obsesión de Mendizábal por sus víctimas (principalmente por Külpe) solo puede traducirse en deseo homoerótico. Y esta aseveración pone nervioso a Mendizábal, quien, hasta ese momento, se presenta como un hombre heterosexual, cuyo interés por Külpe es únicamente profesional.

\section{Siguiendo a Külpe}

En el devenir de la historia, la investigación de Mendizábal se irá alejando del carácter profesional para develar una atracción creciente hacia Külpe. Desde el momento en el que recibe su fotografía, se percibe que esta genera una fascinación especial en Mendizabal:

Pegado al dorso de la ficha había un pequeño sobre con una foto adentro. Mendizábal la observó con fascinada atención. Era un rostro interesante el de Külpe. Esos cabellos (se sorprendió Mendizábal al pensarlo) debían brillar intensamente bajo el sol del mediodía. Los ojos le produjeron una especie de náusea o vértigo. La boca, los labios delgados pero sensuales, se arqueaba en un gesto leve de soberbia (2013: 16).

La detallada descripción de los labios "sensuales" y la sensación de vértigo provocada por sus ojos introduce en el relato una serie de subversiones en relación con el género: el eje heterosexual aparece desplazado y el erotismo se presenta en la relación entre víctima/victimario, roles cumplidos por dos hombres. Desde ese primer encuentro con Külpe, Mendizábal se dejará arrastrar por esa atracción que se irá transformando en una obsesión:

Lo primero era resolver el problema de la distancia. Quería estar junto a Külpe, entregarse a la fiesta excitante y secreta de conocer lo que él ignoraba, de observarlo, sentirlo vivir, y saberse a la vez dueño absoluto de su destino (2013: 19).

A partir de ese momento, los recorridos de Mendizábal estarán marcados por el mapa de Külpe. Es decir, esos espacios que habita y que lo definen: "no hay más que saber trazar su geografía para dominarlo" (2013: 63).

En un primer momento, todo parece indicar que el acercamiento de Mendizábal a su víctima está emparentado con su trabajo y que existe solamente un interés criminal: el saberse dueño de una vida que él puede terminar cuando quiera. En distintas oportunidades, esta idea se establece, por ejemplo, cuando se explica el motivo de 
uso de la Luger (para sentirse verdaderamente ejecutor de la muerte). Pero, a la luz de cómo el sicario mira a su víctima, también se manifiesta que lo que Mendizábal persigue es controlar a Külpe, y de alguna manera, poseerlo:

Aunque, sin embargo, había algo. Un miedo quizá indefinible, pero sin dudas referido a la posibilidad de perderlo a Külpe. Y era aquí, exactamente aquí, cuando lo asaltaba una especie de desesperación por matarlo, como si solamente a partir de este hecho pudiera tenerlo, por fin, seguro para siempre (2013: 70).

El deseo de posesión se canaliza, al inicio, a través de las fotografías que le toma en distintas circunstancias. Susan Sontag señala que:

Hay algo depredador en la acción de hacer una foto. Fotografiar personas es violarlas, pues se las ve como jamás se ven a sí mismas, se las conoce como nunca pueden conocerse; transforma a las personas en objetos que pueden ser poseídos simbólicamente (2013: 24).

En síntesis, es apropiarse del fotografiado, desprenderlo de su propia existencia para formar parte de la de quien fotografía y, además, hacerlo de manera furtiva, teniendo total control de la víctima. El recorte que Mendizábal realiza en las fotos expresa el modo en el que su víctima se ha transformado en objeto de deseo:

Abandonó toda imagen que no fuera el rostro de Külpe. No le importó más el niño, ni la mujer claudicante, ni las escalinatas o la glorieta de las Barrancas. Sólo Külpe. Su rostro, primero, y después, separadamente, cada una de sus partes: los labios, la frente, la nariz, los ojos. Sobre todo los ojos. Trabajó hasta el agotamiento, perpetrando una ampliación tras otra, dominado por un profundo sentimiento de poder y de victoria. Ese rostro se le sometía (2013: 25).

La focalización en el rostro de Külpe, que se recorta de todo lo que lo rodea, se convierte, momentáneamente, en una forma de concretar su dominación por sobre ese otro que encarna su fascinación. La fotografía "es uno de sus secretos más íntimos" (2013: 103) que es desenmascarado por Peña y que se presenta como un indicio de su deseo por Külpe:

Mire, esto es increíble. Usted nunca le debe haber sacado tantas fotos a un tipo [...] Y después se quiere comparar con nosotros. Nosotros le dimos una fotito de carnet, una mierdita que conseguimos por ahí. En cambio, mire lo que hizo usted [...] fotos de la boca, de la nariz, de los ojos. De los ojos solamente hay como diez. En serio, Mendizábal, por curiosidad nomás, ¿qué tiene con este tipo? ¿Qué le picó? (2013: 109-110)

Peña lee esa actitud como signo de degradación de su hombría. Especialmente la fijación en la mirada de Külpe, esa insistencia en ampliar los ojos. Barthes señala que la fotografía tiene el poder de mirarnos directamente a los ojos (2012: 167). Entonces, Mendizábal canaliza su deseo sobre Külpe con la mirada. No solo él mira a Külpe sino que, gracias a las ampliaciones de sus ojos, este también lo mira. Al interpretar el deseo de Mendizábal, Peña entiende que ya ha captado la debilidad de su enemigo.?

7 Es interesante el papel de la lectura en la novela. En principio, Últimos días de la víctima abre con dos epígrafes. Uno de ellos corresponde a "La muerte y la brújula" de Borges. En este cuento, la relación con la lectura es muy importante porque es el tópico del policial que se revierte. Es decir, el detective, Lönnrot, es quien hace la mala lectura que lo lleva a su muerte. Y el comisario, Treviranus, el que hace la correcta y resuelve el primer crimen. En la novela de Feinmann se repite este motivo. Mendizábal, que es más culto, es quien lee mal y no puede desentrañar las intenciones de Külpe. En cambio, Peña, que carece de sutilezas, es realmente quien puede leer a su adversario. El motivo de la capacidad del detective de leer los indicios del crimen y al criminal es constitutivo del género desde sus orígenes. Se trata de una lectura alegórica: el investigador como aquel que es capaz de leer las huellas del 
En este afán de perseguir este objeto de deseo, las fotografías se vuelven insuficientes y decide ingresar al departamento de su víctima. Mendizábal recorre por primera vez el departamento que ha estado vigilando desde que comenzó su investigación y se propone dejar una marca para dar cuenta de que estuvo allí: una pequeña, casi imperceptible, quemadura de cigarrillo. Ese acto -realizado con "excitante lógica" (2013: 28)-conlleva una fuerte connotación erótica: "Fue hacia la ventana y se arrodilló junto a un extremo de la cortina, el izquierdo. Allí, exactamente en el borde, practicó con la punta ardiente de su cigarrillo un milimétrico orificio" (2013:29). Lo que se devela en este gesto es un signo que da cuenta de esa primera penetración simbólica que se inscribe en el mundo de Külpe.

En la segunda incursión al departamento de su víctima el acto sexual vuelve a presentarse de manera simbólica. Cuando ingresa, encuentra unos vasos de whisky que Külpe y Cecilia, su amante, han dejado en la habitación. Uno de ellos está manchado con el rouge de Cecilia. Mendizábal toma el vaso y experimenta una fantasía sexual, en un primer momento, ambigua: "Después se puso de rodillas, colocó sus labios sobre la mancha de rouge, y comenzó, lentamente, a pasarle la lengua. Lo hizo con los ojos cerrados, transpirando" (2013: 49). Las alusiones a la penetración son explícitas:

Se concentró, se dejó penetrar por las sensaciones que recibía: el gusto dulzón, la consistencia leve y cremosa del rouge, la humedad de su mano contra el vidrio del vaso, la cabeza blanda, las rodillas firmes contra el piso, sosteniéndolo, esa calidez entre las piernas. Todo le confirmaba la presencia de su propio cuerpo. Podría haber permanecido así durante mucho tiempo. Sobresaltado, casi con vergüenza, comprobó entonces su erección (2013: 49). (Subrayado nuestro).

En este pasaje, puede interpretarse, al inicio, que Mendizábal siente deseo hacia Cecilia. Sin embargo, si prestamos más atención, es posible ver que Mendizábal desea ocupar el lugar de Cecilia, ser ella. En la lectura que realizamos, consideramos plausible esta segunda interpretación debido tanto a la forma en la que se describe el cuerpo de Mendizábal en dicha práctica, como al modo en el que esta experiencia lo afecta. Judtih Butler (2001) caracterizó cómo, dentro de los marcos de un sistema heterocentrado, se establecen normas hegemónicas del género que delimitan la masculinidad de la femineidad. Estas normativas binarias se plasman en discursos y prácticas a partir de las cuales se configura, en términos de Preciado (2011), el sistema sexo-género. Leído desde esta matriz heteronormativa, la posición del cuerpo que adopta el personaje al transitar su experiencia sexual es censurada por él al sentir que se aparta de los patrones de masculinidad hegemónica. Y, en este sentido, la vergüenza de sentirse excitado reforzaría que el objeto de deseo es Külpe y no Cecilia.

Cabe recordar que Külpe se relaciona con dos mujeres: Amanda y Cecilia. La primera es con quien se encuentra en las Barrancas (junto a su hijo) y con la que parece haber terminado una relación; mientras que Cecilia es su amante que lo visita frecuentemente en su departamento. Mendizábal intenta acercarse a ambas, pero no lo logra. De hecho, parece ser incapaz de sostener ningún tipo de vínculo con las mujeres,

crimen en la gran ciudad (Benjamin, 2012; Allewyn, 1982; Frisby, 2007). Esta mirada convive con la caracterización del detective como lector empírico, tal como lo plantea Piglia en El último lector: “Dupin es antes que nada un gran lector, un nuevo tipo de lector. Como en Hamlet, como en Don Quijote, la melancolía es una marca vinculada en cierto sentido a la lectura, al exceso de los mundos irreales, a la mirada caracterizada por la contemplación y el exceso de sentido" (2005: 80).

8 Paul B. Preciado sostiene: "El sistema de sexo-género es un sistema de escritura. El cuerpo es un texto socialmente construido, un archivo orgánico de la historia de la humanidad como historia de la producción-reproducción, en la que ciertos códigos se naturalizan, otros quedan elípticos y otros son sistemáticamente eliminados o tachados. La heterosexualidad, lejos de surgir espontáneamente de cada cuerpo recién nacido, debe reinscribirse o reinstituirse a través de operaciones constantes de repetición y de recitación de los códigos (masculino y femenino) socialmente investidos como naturales" (2011: 18). 
especialmente de relacionarse sexualmente con ellas. Esto se manifiesta, sobre todo en el encuentro con Lupe, la prostituta que canta tangos en el boliche al que acuden Cecilia y Külpe. Ella le propone que pasen la noche juntos, pero Mendizábal, lejos de sentirse atraído, experimenta una especie de incomodidad:

-Pero, mirá, dame una mano. -Sin esperar a que él reaccionara, tomó una de sus manos y la colocó sobre su muslo derecho. Dijo: -Dale, no tengas miedo, tocá. -Él acarició el muslo. Primero suavemente, después con fuerza. Ella sonrió y dijo:-Qué tal. Está firme todavía, ¿eh? Y te digo más: estoy toda así. Diez puntos, pichón.

-Se te ve bien -asintió él, y apartó la mano (2013: 166).

Luego, en cuanto se presenta la oportunidad, Mendizábal abandona el dancing y literalmente huye de Lupe. Por su parte, la mirada sobre Cecilia se acerca más a los celos que al deseo:

La vio entonces apretar su cuerpo contra el de Külpe y besarlo en la boca. Sintió un malestar intenso. ¿Por qué había hecho eso? Por oscura que estuviera la calle, ¿era necesario hacerlo allí? Paralizado y aturdido, la vio después deslizar sus manos por los cabellos y el cuerpo de Külpe hasta detenerse entre sus piernas. Entonces, la escuchó reír.

¿Estaba ocurriendo realmente todo eso? ¿Qué clase de mujer era Cecilia? ¿Y qué clase de hombre era Külpe para aceptar ser utilizado, vejado, agredido en tal forma? Los vio entrar en el edificio. Ardientes e insultantes, así entraron (2013: 33).

La indignación de Mendizábal se dirige solo a la actitud de Cecilia y si bien dice que ambos entraron "ardientes e insultantes" es notorio que, en la descripción, Cecilia lleva la mayor connotación negativa. Külpe es vejado y es ella quien lo toca, lo avan$z a$, exhibe su sexualidad. El cuerpo de Külpe se transforma en un campo de disputa con Cecilia y esto vuelve a poner en cuestión, para el personaje, su masculinidad. A medida que la novela se desarrolla, los sentimientos hacia Külpe lo confunden: "Antes, a lo sumo, los trabajos se resolvían con un riguroso seguimiento, un par de fotos y un balazo bien colocado. Ahora no: esto era distinto. Pero, ¿por qué? No lo sabía" (2013: 149). La atracción hacia Külpe se torna más intensa y esa fascinación y deseo de posesión de su víctima, que excede a todo lo que ha realizado antes, es lo que sostiene la rivalidad con Cecilia. Si analizamos esto, en términos de Breu (2005), en el relato se desplazan los ejes sobre los que se estructura la trama narrativa del policial negro: el deseo erótico se traslada a otro hombre, su víctima, mientras que la rivalidad se dirime con la femme fatale y esa rivalidad se disputa sobre el cuerpo de Külpe. Esa disputa, tanto como su deseo por Külpe, socava el régimen sobre el que se sustenta su hombría:

Comenzó a golpearla con la culata del arma, compulsivamente, sin poder detenerse. La mujer, ahora, apenas si soltaba uno que otro quejido y ni siquiera atinaba a protegerse. Cayó finalmente a los pies de Mendizábal, quien, exhausto, retrocedió hasta recostarse contra una de las paredes (2013: 221).

Para Connel (1995), la masculinidad siempre se define en relación con lo femenino. Es decir, la masculinidad constituye un concepto relacional que no existe sino en contraste con el de femineidad. En esta línea, la masculinidad hegemónica se presenta como un patrón de prácticas sociales que permiten la continuidad del dominio masculino sobre las mujeres (Connel y Messerchmidt, 2005: 829-859). Hacia el final, la golpiza dada a Cecilia no solo legitima -a partir de una práctica de carácter normativo- la subordinación de las mujeres a los hombres; sino 
que se transforma en una de las últimas formas de recomponer su masculinidad amenazada." Sostener las formas en las que se entrama "lo masculino" en cada contexto particular requiere de un trabajo constante que impida la intrusión de lo no-masculino, que se presenta como amenaza. Estos ideales reguladores (Preciado, 2011), que son los modelos de femineidad y masculinidad, negocian su continuidad a través de la reiteración de un conjunto de prácticas que le otorgan sentido. La violencia desatada sobre el cuerpo de Cecilia se expresa, en ese sentido, como una práctica que legitima y refuerza para Mendizábal su masculinidad ante el resto de los hombres.

En el desarrollo de la novela, las mujeres de Külpe se presentan, también, como una vía de acceso a él y su atracción se funda precisamente en ese rasgo. La relación con Amanda se plantea en ese sentido: poseer a Amanda es llegar a Külpe. Esto se revela en el encuentro con ella en el parque:

Con fascinación, con temor, con asombro, había vuelto a tomar conciencia de un hecho absoluto: ella era la mujer de Külpe. Esa boca grande, cálida y carnal, que él estaba mirando ahora, había sido besada o mordida infinitas veces por Külpe. Esas manos, que él ahora -en un acto quizás insensato pero posible- podía tomar entre las suyas, habrían recorrido incansablemente, con avidez y sin duda con impudicia, el cuerpo de Külpe. Esa voz, que él acababa de escuchar, era la misma voz que habría expresado a Külpe, innumerables veces también, sentimientos de amor, de odio o venganza.

En ese exacto momento, estremecido, comprendió que en cada cosa de ella que él pudiera recibir, por ínfima que fuese, habría algo de Külpe (2013: 80).

Amanda solamente es el nexo para relacionarse con Külpe. De ahí que Mendizábal, hacia el final de la novela, al constatar que Külpe no se ha refugiado con ella, y no puede recuperarlo a través suyo, simplemente la abandona.

\section{Mendizábal/ Külpe: víctimas y victimarios}

En la tercera incursión de Mendizábal al departamento de Külpe tiene lugar otro suceso singular. Al ingresar, Mendizábal encuentra dos nuevos elementos: un teléfono, que cobrará importancia en el desenlace y, colgado en una silla, un saco azul, con botones plateados, que había usado Külpe los días anteriores. Al verlo, Mendizábal se para frente a un espejo y se viste con el saco de su víctima. Se queda "largamente mirándose frente al espejo" y descubre que "las mangas eran un poco largas, los hombros se le ajustaban más de lo deseado, pero no le quedaba mal ese saco" (2013: 153). El cambio de vestuario y el espejo instalan en la historia una duplicidad entre víctima y victimario, a la vez que expresan la fusión, deseada por Mendizábal, entre ambos. Es interesante observar los significados que se configuran a partir de esta escena. Martínez Expósito (1998), luego de analizar las configuraciones homoeróticas en la literatura española, afirma que en estas narraciones los espejos se presentan tanto como vehículos para la búsqueda de identidad, como metáforas visualizadas de la inversión. Esta apropiación simbólica de Külpe, a través de su vestimenta, es,

9 En este punto es pertinente pensar en el concepto de violación alegórica de Rita Segato. En este hecho no se produce un contacto que pueda calificarse de sexual, pero sí hay intención de abuso y manipulación indeseada del otro (2003: 40). Entonces, Mendizábal abusa de Cecilia, de su cuerpo, al golpearla salvajemente. Este abuso del cuerpo consiste en una violación alegórica porque representa la necesidad de aleccionar a la mujer. Segato sostiene que este tipo de violación "se percibe como un acto disciplinador y vengador contra una mujer genéricamente abordada. El mandato de castigarla y sacarle su vitalidad se siente como una conminación fuerte e ineludible. Por eso la violación es además un castigo y el violador, en su concepción, un moralizador" (2003: 31). 
al mismo tiempo, la expresión del deseo de encuentro con el otro, como un signo de la duplicidad entre los personajes. Una duplicidad que se enfatizará hacia el final del relato.

Luego de este episodio, en la novela, se precipitan los acontecimientos. Mendizábal se ve presionado por el hombre importante para terminar su misión -algo que ha venido postergando desde el inicio- y la trampa a su alrededor se va cerrando. Ensaya las últimas palabras que le dirá a Külpe, pero no termina de llevar a cabo el asesinato. Cuando toma la decisión, ingresa nuevamente al departamento y encuentra que Külpe lo ha abandonado: "Lo había perdido" (2013: 211). A partir de este momento, asistimos al derrumbe de Mendizábal. Pierde el control: "Algo en su cabeza, repetía: Külpe se fue, Külpe se fue" (2013: 216). Para recuperarlo, recorre todos los "espacios de Külpe": la agencia de Prode y Lotería, el local de diversión nocturna Annie Malone dancing, la casa de Amanda; y en ese último recorrido la violencia se acrecienta. Pierde esa profesionalidad de la que se jactaba ante Peña y que se basaba en la planificación escrupulosa y pulcra del crimen. Desde la pérdida de Külpe, todo en él se desborda: golpea a Cecilia, se expone ante Amanda, asesina a Morales.

Ese desborde se expresa también en la novela a través de la reiteración de la lluvia. La mención a la lluvia comienza en el momento en el que está revelando las primeras fotos de Külpe y, a partir de allí, cada recuerdo o visión de su víctima aparece mediado por la lluvia (2013: 24-31-33-54-55-153-205). Cuando está escribiendo lo que va a decirle a Külpe "un trueno inmenso estalló afuera" (2013: 207) y a partir de su desaparición, la lluvia se convierte en torrencial. Todo el recorrido en que se manifiesta su desesperación lo realiza bajo esta lluvia torrencial, símbolo que daría cuenta, en función del contexto, del estado emocional del protagonista, pero también de la dimensión de su deseo homoerótico. ${ }^{10}$ Finalmente, cuando se dirige por última vez al departamento de Külpe en el que encontrará la muerte, la luna misma adquiere el color de la sangre: "Una luna rojiza asomaba por entre los nubarrones densos y oscuros" (2013: 256).

En ese último ingreso se devela la trampa: las fotografías del victimario, ahora víctima, se despliegan ante su vista:

La habitación estaba totalmente cubierta con fotografías que mostraban su imagen: Mendizábal saliendo del chalecito de la calle Lugones; Mendizábal en la puerta residencial; Mendizábal en las Barrancas, sentado en un banco, solo; Mendizábal abriendo la puerta de entrada del edificio de Külpe; Mendizábal saliendo de la casa del hombre importante; Mendizábal en la esquina del Albor, esperando a Peña; Mendizábal sentado en el banco de la estación; Mendizábal otra vez en las Barrancas, pero con Amanda ahora, y con Sergio, y el barrilete; Mendizábal entrando al Strómboli; Mendizábal frente a la agencia de Prode y Lotería; y, finalmente, el rostro de Mendizábal, y también sus ojos, muchas veces sus ojos" (2013: 258).

Las fotografías evidencian la trampa que se le ha tendido, pero también dan cuenta del carácter especular de ese juego que se establece entre ellos. Ambos cumplen la función de víctima/victimario. El modo de actuar de Külpe refleja el de Mendizábal: el perseguidor se convierte en perseguido. En esta inversión se trama, de alguna manera, el tipo de vínculo que se establece entre ellos. También Külpe fotografía el rostro y

10 Seguimos aquí a Elena Oliveras, quien sostiene que todo símbolo se configura como tal en relación con la función que cumple en una obra artística. Para identificarlo es necesario tener en cuenta dos principios: el principio de congruencia, que se refiere tanto a la acentuación (repetición en la literatura) como a su desvío, y el principio de congruencia, que da cuenta de una selección de connotaciones que mantienen coherencia con el contexto. Estos elementos adquieren su carácter simbólico debido al excedente de significación que producen y a la relación que sostienen con su contexto de aparición (2011: 81-104). 
los ojos de Mendizábal ("muchas veces sus ojos"), ingresa a su departamento, deja una marca similar a la que había hecho Mendizábal, repite sus palabras y finalmente, en un último acto de posesión, lo mata.

En ese final, más allá del retorno al tópico del cazador-cazado -transitado desde períodos tempranos en el policial- es posible leer también un desvío de algunos de los elementos del género. En ese sentido y con una mirada orientada hacia la construcción de la masculinidad, Últimos días de la víctima presenta una variación interesante respecto del mundo masculino propuesto en el género negro. Retomando la perspectiva de Breu (2005), al eje homosocial -configurado a partir de los valores de una masculinidad hegemónica, que se expresa en el hardboiled a través de vínculos marcados por la competencia y el conflicto- se incorpora el homoerotismo, y se soslaya al eje heterosexual al reducir el mundo femenino a una dimensión instrumental. En ese desplazamiento emerge una nueva masculinidad que, negada por el mismo protagonista, se resuelve solo a través de la muerte.

\section{Consideraciones finales}

La novela de Feinmann configura, en un momento particular del género en nuestro país, una variación novedosa respecto de los modelos del hardboiled. Dicha variación da cuenta de la exclusión del protagonista de un mundo construido bajo una lógica en la que el poder se configura en torno de un tipo de masculinidad particular. La pérdida de ese lugar coincide con el momento en el que Mendizábal se da cuenta de que no puede escapar a su deseo. La tensión sexual que genera Külpe en Mendizábal problematiza la visión de hombre duro del protagonista. Esto mismo se ve reflejado en los constantes enfrentamientos que entabla con Peña, quien ataca reiteradamente su hombría. Por eso, podemos arribar a la conclusión de que, en la novela, las jerarquías de poder y la capacidad de cumplir con las tareas también están circunscriptas a la construcción de la masculinidad.

Si recuperamos la lectura que la crítica ha realizado en clave política relacionando la novela con la dictadura (Jakovskis, 2011), la construcción de esta masculinidad, en conflicto con los modelos dominantes -propios de los "sujetos policiales" (Sirimarco, 2004)- constituye una forma de leer el género políticamente. En este sentido, Feinmann conjuga las relaciones de poder y el deseo como factores fundamentales de las transformaciones que la serie literaria del negro en nuestro país realiza en esos años. 


\section{Bibliografía}

" Allewyn, R. (1982). “Origen de la novela policíaca”. En: Problemas y figuras. Barcelona: Editorial Alfa, 205-222.

" Barthes, R. ([1980] 2012). La cámara lúcida. Notas sobre la fotografía. Buenos Aires: Paidós.

"Benjamin, W. (2012). El París de Baudelaire, Buenos Aires: Eterna Cadencia.

»Borges, J. L. ([1942] 2016). “La muerte y la brújula”. En: Cuentos completos. Buenos Aires: Debolsillo, 187-199.

» Borges, J. L. ([1949] 2016). “El muerto”. En: Cuentos completos. Buenos Aires: Debolsillo, 247-252.

» Bourdieu, P. (2000). La dominación masculina. Barcelona: Anagrama.

»Breu, C. (2005). Hard Boiled Masculinities. Minneapolis: University of Minnesota.

"Butler, J. (2001). El género en disputa. El feminismo y la subversión de la identidad. México: Paidós.

"Calabrese, E. (2000). "Gestos del relato: el enigma, la observación, la evocación”. En: Jitrik, N. (dir.), História crítica de la Literatura Argentina, tomo 11, La narración gana la partida, Drucaroff, E. (dir.). Buenos Aires: Emecé, 73-96.

"Connel, R. (1995). Masculinities. Berkeley y Los Angeles: University of California.

»Connell, R. y J. Messerchmidt (2005). "Hegemonic Masculinity: Rethinking the Concept". Gender and Society, 19.6, 829-859.

»De Rosso, E. (2018). "El octavo círculo: ficciones policiales argentinas". En: Jitrik, N. (dir.) Historia crítica de la Literatura Argentina, tomo 12, Una literatura en aflicción, Jorge Monteleone (dir.). Buenos Aires: Emecé Editores, 617-652.

" Feinmann, J. P. (1991). “Estado policial y novela negra argentina”. En: Petroni, G., J. Rivera y L. Volta (eds.), Los héroes difíciles: Ia literatura policial en Argentina y en Italia. Buenos Aires: Corregidor, 141-147.

" Feinmann, J. P. ([1979] 2013). Últimos días de la víctima. Buenos Aires: Booket.

"Feinmann, J. P. ([1981] 2014). Ni el tiro del final. Buenos Aires: Planeta.

» Frisby, D. (2007). Paisajes urbanos de la Modernidad. Bernal: Universidad Nacional de Quilmes.

»Gandolfo, E. ([1986] 2017). "Perdónalos, Marlowe, porque no saben lo que hacen”. En: El libro de los géneros recargado. Buenos Aires: Blatt y Ríos, 213-217.

»Gandolfo, E. (1974). "Sobre El agua en los pulmones de Juan Martini". Hyspamérica, nำ8, octubre, 97-98.

» Giardinelli, M. ([1984] 2013). El género negro: orígenes y evolución de la literatura policial y su influencia en Latinoamérica. Buenos Aires: Capital Intelectual.

» Grella, G. (1980). “The Hard-Boiled Detective Novel”. En: Winks, R. (ed.), Detective Fiction. New Jersey: Englewood Cliffs, 103-120.

» Jacovski, N. (2011). “Novela negra y estado de excepción en Argentina: Últimos días de la víctima, de José Pablo Feinmann". Arizona Journal of Hispanic Cultural Studies, 41-59. 
》 Lafforgue, J. (1988). Represión y reconstitución. Buenos Aires: Eudeba.

"Lafforgue, J. y J. Rivera ([1977] 1997). Asesinos de papel. Ensayos sobre narrativa policial. Buenos Aires: Colihue.

" Martínez Expósito, A. (1998). Los escribas furiosos. Configuraciones homoeróticas en la narrativa española. Nueva Orleans: UniversityPress of the South.

»Oliveras, E. (2011). La metáfora en el arte: retórica y filosofía de la imagen. Buenos Aires: Emecé.

»Piglia, R. (2005). “Lectores imaginarios”. En: El último lector. Barcelona: Anagrama, 77-102.

»Piglia, R. ([1976]2015). “Sobre el género policial”, En: Crítica y ficción. Buenos Aires: Anagrama, 59-68.

"Preciado, P. B. (2011). Manifiesto contrasexual. Barcelona: Anagrama.

"Sebreli, J. J. ([1959] 1997). "Dashiell Hammett o la ambigüedad”. En: Escritos sobre escritos, ciudades bajo ciudades. Buenos Aires: Sudamericana, 223-232.

»Segato, R. (2003). Estructuras elementales de la violencia. Ensayos sobre género entre la antropología, el psicoanálisis y los derechos humanos. Bernal: Universidad Nacional de Quilmes.

» Sirimarco, M. (2004). "Marcas de género, cuerpos de poder. Discursos de producción de masculinidad en la conformación del sujeto policial". Cuadernos de Antropología Social, 20, 2004, 61-78.

»Sontag, S. ([1977] 2013). Sobre la fotografía. México: Random House Mondadori. 